\title{
O PSICÓLOGO E O COMPROMISSO SOCIAL NO CONTEXTO DA SAÚDE COLETIVA ${ }^{1}$
}

Magda Dimenstein*

RESUMO. Esse trabalho objetiva desenvolver uma reflexão em torno de algumas questões que vêm sendo amplamente discutidas no campo da saúde coletiva, e que se configuram como enormes desafios para gestores e profissionais de saúde ligados ao Sistema Único de Saúde (SUS) no Brasil. Trata-se, não só, da mudança no perfil profissional das categorias envolvidas com o trabalho da saúde, mas principalmente da transformação de tais profissionais em agentes de mudança a partir de um compromisso social perante o ideário do sistema de saúde e seus usuários. Nesse sentido, pretende-se discutir, mais especificamente, o lugar da psicologia e as práticas realizadas no campo da assistência pública à saúde e seus desdobramentos em termos do compromisso social hoje almejado para a categoria. Para tanto, serão tomados como eixos de análise os resultados de duas investigações realizadas com psicólogos que trabalham na rede básica de saúde das cidades de Natal/RN e Teresina/PI.

Palavras-chaves: compromisso social, psicólogo, saúde coletiva.

\section{THE PSYCHOLOGIST AND THEIR SOCIAL COMMITMENT IN THE COLLECTIVE HEALTH CONTEXT}

\begin{abstract}
The aim of this paper is to reflect on some issues currently under discussion in the field of collective health, and which represent a great challenge for health managers and professionals of the Brazilian Unified Health System. This paper focuses not only on the profile changes that are needed of all health professionals, but rather on the transformation of these professionals into socially committed agents responsible for the renovation of the ethos of the Brazilian Health System and its clients. A more in-depth discussion of the psychologist's place in such a context, his practice within public health care, and on the much-desired social commitment is carried out. The analytical tools that will be used are the results of two investigations that were conducted with psychologists that work in the basic health care network of the cities of Natal, in the state of Rio Grande do Norte, and Teresina, in the state of Piauí.
\end{abstract}

Key words: social commitment, psychologist, collective health.

\section{INTRODUÇÃOO}

Este trabalho objetiva desenvolver uma reflexão em torno de algumas questões que vêm sendo amplamente discutidas no campo da saúde coletiva ${ }^{1}$, e que se configuram como enormes desafios para gestores e profissionais de saúde ligados ao Sistema Único de Saúde (SUS) no Brasil. Trata-se não só da mudança no perfil profissional das categorias envolvidas com o trabalho da saúde, mas principalmente da transformação de tais profissionais em agentes de mudança a partir de um compromisso social perante o ideário do sistema de saúde e seus usuários. Nesse sentido, pretende-se discutir, mais especificamente, o lugar da psicologia e as práticas realizadas no campo da assistência pública à saúde e

\footnotetext{
Este trabalho contou com o apoio financeiro do CNPq (Bolsista de IC/Balcão).

* Professora do Departamento de Psicologia da Universidade Federal do Rio Grande do Norte (UFRN). Dra. em Saúde Mental pelo Instituto de Psiquiatria da UFRJ.

Endereço para correspondência: UFRN, CCHLA, Depto. de Psicologia, sl.607, campus universitário, CEP 50.078-970, NatalRN. E-mail: magdad@uol.com.br

2 Podemos entender a Saúde Coletiva, segundo Paim e Almeida Filho (2000), como "campo científico, onde se produzem saberes e conhecimentos acerca do objeto 'saúde' e onde operam distintas disciplinas que o contemplam sob vários ângulos; e como âmbito de práticas, onde se realizam organizações e instituições por diversos agentes (especializados ou não) dentro e fora do espaço convencionalmente reconhecido como "setor saúde" (p.60).
} 
seus desdobramentos em termos do compromisso social hoje almejado para a categoria. Para tanto, serão tomados como eixos de análise os resultados de duas investigações realizadas com psicólogos que trabalham na rede básica de saúde das cidades de Natal/RN e Teresina/PI.

\section{A CONSTRUÇÃO DE NOVOS SUJEITOS E PRÁTICAS EM SAÚDE: EM QUESTÃO O COMPROMISSO SOCIAL}

\begin{abstract}
No lugar deste risco que deve ser corrido (a existência humana é um risco) e que também caracteriza a coragem do compromisso, a alienação estimula o formalismo, que funciona como uma espécie de cinto de segurança (Freire, 1998, p. 25).
\end{abstract}

O SUS pode ser considerado uma das principais inovações da reforma do Estado Brasileiro. É fruto de um amplo processo de discussão em relação à situação de saúde do país, o qual envolveu o Governo, profissionais de saúde progressistas e a população. A VIII Conferência Nacional de Saúde, ocorrida em 1986, representa um marco na luta pela melhoria do sistema de atenção à saúde no Brasil ,na medida em que se constituiu como o espaço de negociação e definição do SUS enquanto política nacional. Observa-se que, ao longo dos últimos anos, vem se desenhando no setor saúde uma nova relação entre Estado e sociedade, onde se torna mais visível a presença de uma diversidade de atores, cada qual com seus interesses e projetos próprios, relação que pode propiciar um maior controle público sobre a assistência que é prestada à população, na medida em que passa a ser sujeito ativo e co-responsável pelos rumos tomados pela saúde pública no país.

É nesse contexto que as questões relativas à avaliação e à satisfação do usuário com o serviço de saúde tornaram-se importantes, pois considera-se que a modificação do modelo assistencial hegemônico e a melhoria real no atendimento à saúde passam necessariamente pelo desenvolvimento de serviços mais próximos da população, das suas necessidades e prioridades. Para isso, exige-se uma nova mentalidade profissional e organizacional, participação e compromisso na busca da qualidade da saúde. Ou seja, é preciso uma reconstrução da subjetividade dos trabalhadores do campo da saúde, bem como alterar a cultura organizacional hegemônica (Dimenstein,1998), sendo esse, então, o grande desafio que a Reforma Sanitária enfrenta no país.
Em outras palavras, em se tratando dos Recursos Humanos, temos dificuldades não só em termos da formação profissional, organização e gestão, mas principalmente, no sentido de "erradicar o desinteresse, a alienação, o agir mecânico e burocratizado" (Campos,1994,p.43) que estabelece um nítido distanciamento dos trabalhadores entre si e com os usuários dos serviços de saúde. Estamos falando da falta de compromisso do profissional com as instituições de saúde, com a qualidade e humanização ${ }^{3}$ das práticas, com o acolhimento e vínculo com os usuários, aspectos considerados fundamentais para a transformação dos modos hegemônicos de fazer saúde e para a construção de um sistema de saúde universal, integral e equânime.

Tal quadro é conseqüência de uma série de fatores que vêm se apresentando ao longo dos anos, entre os quais estão: a redução dos investimentos no setor saúde pelo poder público; os insuficientes investimentos na formação, capacitação e educação continuada dos trabalhadores de saúde tendo em vista novas práticas sanitárias; a falta de integração do aparelho formador com a nova realidade dos serviços; a heterogeneidade das políticas de Recursos Humanos nos três níveis de poder, com discrepância quanto à remuneração, jornada de trabalho, plano de carreira e salários e, principalmente, à falta de participação do trabalhadores como co-responsáveis pela gestão do SUS.

Em decorrência disso, nos deparamos com profissionais descontentes, frustrados, apáticos diante da miséria social onde está inserida grande parcela da população brasileira, organizados em torno de interesses imediatos e corporativistas, enfraquecidos em sua capacidade de resistência e luta em prol da cidadania; profissionais impedidos de comprometer-se verdadeiramente com um novo projeto de sociedade e de saúde pública.

Mas, afinal, o que vem a ser um profissional comprometido? Que idéia de compromisso deveria fundamentar as ações de saúde desenvolvidas dentro do SUS? Que valores cabe a nós estimular no sentido de orientar os saberes e práticas profissionais no âmbito da assistência pública à saúde? Tomando Paulo Freire (1998) como referência, podemos dizer que compromisso implica necessariamente em uma

\footnotetext{
3 Tomamos como referência a concepção de humanismo posta por Freire (1998): "O humanismo é um compromisso radical com o homem concreto. Compromisso que se orienta no sentido de transformação de qualquer situação objetiva na qual o homem concreto esteja sendo impedido de ser mais" (p.22). Afasta-se, conseqüentemente, de qualquer perspectiva assistencialista ou de cunho religioso.
} 
tomada de posição; envolve uma decisão por parte de um Sujeito/Ator Social e ocorre no plano das ações, da realidade concreta. Isso quer dizer, por sua vez, que "A primeira condição para que um ser possa assumir um ato comprometido está em ser capaz de agir e refletir" (p.16). Só um sujeito situado no seu tempo histórico e em relação aos determinantes culturais, políticos e econômicos que condicionam seu modo de estar no mundo poderá transformar, desejar e ousar a mudança, sair do conformismo, reverter a lógica que sustenta o imobilismo, isto é, comprometer-se, ser um ser da práxis. Tal como o processo de alfabetizar-se, que para Freire (1998) está além de saber codificar e decodificar palavras estranhas, e implica em tornar-se alguém capaz de aprender a ler a realidade circundante e escrever a sua própria história, o compromisso social requer um sujeito capaz de construir um saber crítico sobre si mesmo, sobre seu mundo e sobre sua inserção nesse mundo (Martín-Baró,1997). Sujeitos "dinamizadores", segundo a perspectiva de Paim e Almeida Filho (2000), capazes de revolucionar o cotidiano na medida em que acreditam na possibilidade de o novo surgir, na surpresa; sujeitos que recusam o determinismo absoluto que aniquila os possíveis espaços de liberdade, de criação, de diversidade. Tal concepção aproxima-se da noção de "operador" trazida por Rotelli (1990), isto é, pessoas capazes de reconstruir a história de vida dos usuários para além do diagnóstico e do sintoma, trabalhadores ativos no processo de reelaboração do sofrimento e reinvenção da vida. O “operador", nessa perspectiva, volta-se para a qualidade do cuidado, a qual pressupõe acolhida e responsabilidade pela atenção integral da saúde coletiva e individual, e para a criação de estratégias de modificação da realidade dos usuários.

Esses sujeitos são capazes de investir na produção de modos heterogêneos de cuidado, bem como na singularização da atenção, respeitando a diversidade cultural e subjetiva dos usuários, criando vínculos e responsabilidade para com a saúde do público. Tratase, pois, de um profissional não escravizado pela técnica, pelo saber totalizante dos experts, por rituais profissionais, mas norteado por modelos de explicação ampliados acerca do complexo "promoção-saúdedoença-cuidado" (Paim \& Almeida Filho, 2000, p.75), e formas de intervenção flexíveis que levam em conta as necessidades e prioridades de saúde da clientela, e que possui efetiva capacidade para lidar com uma realidade desafiadora e complexa, que não se encontra enclausurada nos modelos teóricos aprendidos na academia.

E o que nós, psicólogos, temos a ver com isso? Essa é uma pergunta que, sem dúvida, parece povoar o campo "psi" muito recentemente. Historicamente, a psicologia sempre esteve "míope" diante da realidade social, das necessidades e sofrimento da população, levando os profissionais a cometer muitas distorções teóricas, a práticas descontextualizadas e etnocêntricas, e a uma psicologização dos problemas sociais, na medida em que não são capacitados para perceber as especificidades culturais dos sujeitos. Nesse sentido, é bastante óbvio que a psicologia veio se configurando como um instrumento útil para a reprodução das estruturas injustas de nossos sistemas sociais, especialmente latino-americanos (Martín-Baró,1997), ou seja, vem servindo de suporte científico das ideologias dominantes, das relações hierarquizadas de poder, e para a manipulação das maiorias pobres por uma minoria, onde os profissionais aparecem como “... cúmplices da já conhecida política de dominação dos mais fracos" (Botomé,1996, p.198).

Ao longo dessa trajetória, o modelo curativo e assistencialista, voltado para o setor dos atendimentos privados foi se consolidando dentro da categoria dos psicólogos, tornando-se o paradigma hegemônico da profissão. Os cursos de graduação tenderam claramente para formar um profissional que atualmente encontra dificuldade em superar as práticas cristalizadas (naturalização de práticas historicamente produzidas) e de adaptar-se às novas exigências de responsabilidade social, aos princípios da qualidade, da ética e da cidadania, postos especialmente pelo setor saúde. Em outras palavras, a formação profissional veio direcionando o psicólogo para modelos de atuação bastante limitados para o setor saúde, modelos responsáveis, em parte, pelas dificuldades do profissional em lidar com a demanda da clientela e das instituições de saúde, e até de adaptar-se às dinâmicas condições de perfil profissional exigidas pelo SUS.

Tais modelos de atuação são menos flexíveis às influências do mercado e às necessidades sociais, pois se encontram muito arraigados à identidade e cultura profissional do psicólogo e ao processo de institucionalização das organizações corporativas ${ }^{4}$. Tanto é que a entrada do psicólogo nas instituições públicas de saúde, apesar de ter ampliado seu campo de trabalho, parece não ter alterado os modelos teóricos e práticos que fundamentam sua atuação. $\mathrm{Ou}$ seja, não houve uma contextualização, revisão ou até mudança nas suas formas tradicionais de atuar. Daí, sua dificuldade em construir novas práticas voltadas

\footnotetext{
4 Sobre esse tema ver Dimenstein (1998); (2000).
} 
para a produção social da saúde e da cidadania, práticas comprometidas com o bem-estar social.

Para ilustrar tal situação, passamos agora aos resultados de uma investigação realizada com psicólogos que trabalham em Unidades Básicas de Saúde nos municípios de Natal/RN e Teresina/PI, cujo enfoque esteve voltado para a questão do comprometimento com o trabalho, o qual está sendo entendido enquanto compromisso ético com a saúde pública, com a promoção do bem-estar social e com a defesa da vida. Tal postura se expressa, entre outras formas, através do uso de recursos técnicos e teóricos contextualizados, de acordo com as características e necessidades da clientela, como também na maneira de relacionarem-se a equipe de saúde e usuários, democrática, não hierarquizada e verticalizada.

\section{DESENVOLVIMENTO DA PESQUISA}

Os dados referentes aos psicólogos de Natal são resultados preliminares de uma pesquisa que faz parte de um Projeto Integrado de Pesquisa que vem sendo desenvolvido pelo Grupo de Estudos em Saúde Mental e Trabalho (GEST) na UFRN. Na primeira etapa da investigação (piloto) foram realizadas entrevistas (semi-estruturadas) com seis (06) profissionais de cada uma das seguintes categorias que compõem as equipes de saúde locais: médicos, enfermeiros, odontólogos, psicólogos, assistentes sociais, nutricionistas. Aqui, vamos nos deter no subgrupo de psicólogos $(\mathrm{n}=06)$. Quanto aos psicólogos de Teresina/PI $(\mathrm{n}=08)$, o levantamento realizado constituiu uma etapa do trabalho de campo desenvolvido nas UBSs, o qual faz parte da Tese de Doutorado da autora (Dimenstein,1998) ${ }^{5}$. As entrevistas, em ambos os municípios, foram feitas nas próprias unidades de saúde. As falas dos profissionais foram analisadas segundo a perspectiva da análise de discurso. Tal análise foi feita segundo a proposta de interpretação qualitativa presente na obra de Minayo intitulada de "método hermenêutico-dialético" (1992, p.218). Esse método de análise parte de alguns pressupostos fundamentais, entre os quais o de que não há observador imparcial e fora da história, de que não existe "a verdade" dos significados escondida no texto, e que uma fala só pode ser entendida se

\footnotetext{
Maiores informações a respeito do mapeamento dos psicólogos em Teresina, consultar o trabalho intitulado "O Psicólogo no Contexto do Sistema Único de Saúde (SUS): Perfil Profissional e Perspectiva de Atuação nas Unidades Básicas de Saúde (UBSs).
}

colocada em seu contexto e no campo da especificidade histórica em que é produzida.

\section{RESULTADOS E DISCUSSÃO}

\section{Perfil profissional}

- São mulheres na sua maioria $(n=12)$, havendo apenas dois homens em Teresina.

Nota-se, por esse resultado, que $86 \%$ dos psicólogos são mulheres, dado compatível com o quadro geral da profissão no país. Mapeamentos como os de Mello (1975), Rosemberg (1983;1984), do Sindicato dos Psicólogos de São Paulo e CRP-06 (1984), CFP (1988) e Castro e Yamamoto (1998), apontaram que a psicologia no Brasil é caracteristicamente uma profissão feminina.

- Ingressaram no serviço público de saúde pela inexistência de opções no mercado de trabalho local, seja através de concurso (04 em Teresina e 05 em Natal), ou de relações pessoais (prestação de serviço);

Segundo os profissionais, o serviço público atualmente configura-se como o maior empregador da categoria de psicólogos. Muitos concordam que as dificuldades para administrar os custos de uma clínica privada são imensos, de forma que é preciso ter um suporte financeiro estável e seguro. Além disso, o serviço público, por sua carga horária flexível, possibilita a realização de outras atividades e não compromete a rotina do consultório ou de outros empregos de uma forma geral. Fica estabelecido, assim, um pacto perverso nas instituições públicas, na medida em que esses diversos vínculos são tolerados e estimulados por parte do poder público, e utilizados como mais uma fonte de renda por parte dos profissionais, que não têm o compromisso de cumprir os horários oficialmente estipulados em seus contratos de trabalho. Tal quadro é mais visível em Teresina do que em Natal:

- Trabalham em média 30h (Teresina) e 40h (Natal) semanais nas instituições públicas de saúde. Os psicólogos de Natal não possuem outros vínculos com instituições públicas de saúde; já os de Teresina exercem mais de uma atividade remunerada em outras secretarias públicas, seja na saúde seja em outras áreas (educacional e organizacional), e até mesmo fora da psicologia;

- encontram-se na situação de assalariamento e têm vários empregos; 
- possuem renda média de 4 a 5 salários mínimos, incluindo salário-base e produtividade;

Quanto à remuneração, nota-se claramente que existem desigualdades enormes entre as diversas categorias profissionais nas instituições públicas de saúde de Teresina e Natal. Os psicólogos, juntamente com assistentes sociais, nutricionistas, terapeutas ocupacionais, fonaudiólogos, entre outros, constituem categorias profissionais que, apesar de ocuparem uma posição relativamente definida na divisão do trabalho em saúde, vivem na condição de subalternidade na hierarquia interna do campo, dominada pela categoria médica.

- São formados majoritariamente em instituições privadas os deTeresina ( $\mathrm{n}=07$ ); já em Natal 05 são formados na UFRN;

- poucos têm formação Pós-Graduada (Especialização: 03 em Teresina e 02 em Natal), nenhum tem Mestrado ou Doutorado;

- as atividades realizadas nas UBSs de Natal envolvem $\mathrm{o}$ atendimento clínico individual e atividades grupais e educativas. Em Teresina predominam a psicoterapia individual, o aconselhamento psicológico e a aplicação de testes.

Pode-se perceber que tais atividades estão conforme o modelo da clínica privada, ao passo que ações de promoção à saúde, desenvolvidas na comunidade, conjuntamente pela equipe multiprofissional, são atividades que não estão sendo desenvolvidas pelos profissionais de psicologia, especialmente de Teresina. Essas mesmas atividades indicadas pelos profissionais foram também as mais citadas pelos psicólogos que participaram da pesquisa realizada por Carvalho (1988) e Boarini (1996), confirmando que são elas que vêm caracterizando a atuação clássica ou tradicional do psicólogo ao longo destes últimos anos. Não fica evidente nas realidades investigadas, tal como colocado pelas pesquisas do Conselho Federal de Psicologia (1988;1992;1994), a presença de novas modalidades de atuação, inclusive mais adequadas às instituições públicas de saúde, voltadas à atenção primária, as quais exigem do profissional saberes produzidos em outras áreas, bem como uma forma diferente de engajamento e de relação com a clientela.

\section{Comprometimento com o Trabalho (CT)}

O CT entre os psicólogos está associado ao cumprimento dos deveres e obrigações que o serviço impõe, tais como pontualidade, assiduidade, obedecer às normas do local, cordialidade, ou seja, ter responsabilidade, não transferindo suas atribuições a outrem. Há uma tendência em associar baixo salário a baixo desempenho e a descompromisso com o trabalho. Atribuem ao poder executivo local a responsabilidade pelo estado em que se encontra o serviço público de saúde, na medida em que não valoriza seu funcionário e não oferece condições apropriadas para que ele execute seu trabalho de forma eficaz. Podemos dizer que a perspectiva predominante entre os profissionais entrevistados em muito difere da concepção de comprometimento enquanto compromisso social, anteriormente discutida. Ou seja, as práticas dos psicólogos não estão norteadas no sentido de construção da cidadania, espaço onde os sujeitos reconhecem, respeitam e convivem com as diversidades dos outros. Além disso, são práticas que não rompem com o esquema tradicional do setor nem oferecem resistência ao enfraquecimento das políticas públicas de saúde mais equalizadoras que se quer concretizar no SUS.

\section{Expressão do comprometimento}

Todos os psicólogos consideram-se comprometidos com o trabalho. Tal compromisso se expressa no cumprimento das tarefas, sendo a principal delas o atendimento clínico individualizado/psicoterapia. Foi possível perceber que os psicólogos se sentem mais à vontade realizando esse tipo de tarefa. É como se sua especificidade profissional em relação a outras categorias presentes na instituição residisse no uso de tal técnica. É então uma ferramenta que garante uma certa diferenciação e proporciona relativo poder ao profissional de psicologia, principalmente porque a maioria dos psiquiatras inseridos nas unidades básicas de saúde não se dedicam à psicoterapia, mas apenas ao tratamento farmacológico. Percebe-se que a psicoterapia termina assumindo um lugar privilegiado dentro do campo da assistência pública à saúde e expressando o que se define por comprometimento com o trabalho.

\section{Fatores que facilitam/dificultam o comprometimento}

Os principais fatores que facilitam uma atitude de comprometimento com o trabalho dizem respeito à identificação com o trabalho, às características de personalidade e valores ético-morais. Por outro lado, para haver comprometimento é preciso que a instituição ofereça boas condições de trabalho, tais como espaço físico e recursos materiais suficientes e adequados. Quanto aos fatores que dificultam o CT, todos os profissionais identificaram os baixos salários recebidos na saúde pública como aquele mais 
significativo. Isto faz com que os profissionais tenham que buscar outros vínculos empregatícios para manter um padrão de renda compatível com suas necessidades. Em seguida identificam na má gerência institucional e administrativa outro fator decisivo para que haja um descompromisso com o trabalho. Os profissionais entendem que a má utilização de recursos financeiros, a incompatibilidade da visão de saúde e a ocupação de cargos por pessoas que desconhecem o contexto da saúde pública prejudicam o bom andamento dos serviços. Nota-se também que, para esses profissionais, a falta de reconhecimento por parte da instituição e dos próprios usuários interfere na questão do envolvimento com o trabalho, pois os profissionais sentem que o seu trabalho não tem a devida relevância social.

\section{CONSIDERAÇÕES FINAIS}

Este trabalho não pretende ser conclusivo a respeito do comprometimento com o trabalho entre os psicólogos. Trata-se de uma aproximação da temática, que aos poucos poderá ser mais aprofundada, à medida que novas investigações, como a que estamos realizando na UFRN, forem fornecendo mais informações sobre a questão. Apesar disso, alguns pontos importantes já podem ser adiantados e servir para incrementar o debate no campo dos recursos humanos em saúde.

Do ponto de vista do processo de trabalho, entendemos que os psicólogos precisam incorporar uma nova concepção de prática profissional, associada ao processo de cidadanização, de construção de sujeitos com capacidade de ação e de proposição. Isso implica em romper o corporativismo, as práticas isoladas e a identidade profissional hegemônica vinculada à do psicoterapeuta. Notamos que o modelo clínico da psicoterapia individual ainda é a forma de trabalho predominante entre os profissionais no setor público, predominância muitas vezes atribuída ao desejo da clientela ou da instituição. Não podemos esquecer que há, de fato, por parte das instituições, um incentivo aos atendimentos individualizados em detrimento de outros tipos de atuação dentro e fora das unidades de saúde, de forma que os profissionais não são incentivados a desenvolver atividades que fogem ao padrão tradicional de atuação atribuído ao psicólogo.

Observamos que a postura do psicólogo que trabalha na saúde coletiva ainda não vem sendo devidamente questionada dentro da própria categoria em termos da sua adequação e efetividade social. Há uma crença na eficácia intrínseca da teoria e da técnica, de maneira que os profissionais não se sentem impulsionados a construir referenciais próprios em busca de uma prática mais contextualizada, ou pelo menos, a questionar o transplante de modelos teóricos e operativos oriundos de outras realidades e outros tipos de clientela. Em outras palavras, a formação acadêmica não tem fornecido elementos para a construção de um profissional-cidadão com possibilidade de intervenção adequada aos espaços territoriais locais, que demandam um alto grau de potência de resposta/ação, de articulação intersetorial, de mobilização de parcerias e de estratégias específicas.

De um modo geral, percebe-se que ser comprometido, para os psicólogos entrevistados, restringe-se ao cumprimento de tarefas que consolidam o modelo de identidade clássico. No panorama atual da saúde coletiva, o compromisso profissional não é uma questão burocrática, mas, especialmente, o desenvolvimento de ações/reflexões cuja intencionalidade prática e política é produzir cidadania ativa, sociabilidade e novas subjetividades. Essa perspectiva nos desafia a pensar em como materilizar essa postura profissional, como fomentar esse ideário em nossos cursos, em nossas pesquisas e nossas produções acadêmicas.....

\section{BIBLIOGRAFIA}

Boarini, M. L.(1996). A Formação (Necessária) do Psicólogo para atuar na Saúde Pública, Psicologia em Estudo, 1, (1), 93-132.

Botomé, S.P. (1996). Serviço à população ou submissão ao poder: o exercício do controle na intervenção social do psicólogo. Estudos de Psicologia, 1, (2),173-202.

Campos, G.W.S. (1994).Considerações sobre a Arte e a Ciência da Mudança: Revolução das Coisas e Reforma das Pessoas. O caso da Saúde. Em Cecílio, L. C. (Org). Inventando a Mudança na Saúde (pp.29-88).São Paulo: Hucitec.

Carvalho, A. A. Ulian, A. L. A. O.; Bastos, A. V. B.; Sodré, L. G. P.; Cavalcante, M. L. P. (1988).A Escolha da Profissão: alguns valores implícitos nos motivos apontados pelos psicólogos. Em CFP: Quem é o Psicólogo Brasileiro? (pp.49-68) São Paulo: Edicon.

Castro, A E. F. e Yamamoto, O. H. (1998). A Psicologia como Profissão Feminina: Apontamentos para Estudo. Estudos de Psicologia, $\underline{3}$, (1), 147-158.

Conselho Federal de Psicologia (1988). Quem é o Psicólogo Brasileiro? São Paulo: Edicon.

Conselho Federal de Psicologia (1992). Psicólogo Brasileiro: construção de novos espaços. Campinas: Átomo.

Conselho Federal de Psicologia (1994). Psicólogo Brasileiro: práticas emergentes e desafios. Rosemary Achcar (Coord), São Paulo: Casa do Psicólogo. 
Conselho Regional de Psicologia/ $6^{\mathrm{a}}$ Região (1995). Psicologia: Formação, Atuação Profissional e Mercado de Trabalho (Estatísticas, 1995). São Paulo.

Dimenstein, M. (1998). O Psicólogo no contexto do Sistema Único de Saúde (SUS): Perfil profissional e perspectivas de atuação nas Unidades Básicas de Saúde (UBSs). Tese de Doutorado, Universidade Federal do Rio de Janeiro.

Dimenstein, M. (2000). A Cultura profissional do psicólogo e o ideário individualista: implicações para a prática no campo da assistência pública à saúde. Estudos de Psicologia , $\underline{5},(1)$, 95-122.

Freire, P. (1998). Educação e Mudança. São Paulo: Paz e Terra.

Martín-Baró, I. (1997). O Papel do Psicólogo. Estudos de Psicologia, 2, (1), 7-27.

Minayo, M. C. S. (1992). O Desafio do Conhecimento. Pesquisa Qualitativa em Saúde. São Paulo, Rio de Janeiro: Hucitec/Abrasco.

Mello, S. L. (1975) .Psicologia e Profissão em São Paulo. São Paulo: Ática.
Paim, J.S; Filho, N. A (2000). A Crise da saúde pública e a utopia da saúde coletiva. Salvador: Casa da Qualidade.

Rotelli, F. \& Nicácio, M. F. (1990). Desinstitucionalização. São Paulo: Hucitec.

Rosemberg, F.(1983). Psicologia: Profissão Feminina. Cadernos de Pesquisa, 47,32-37.

Rosemberg, F.(1984). Afinal, Porque SomosTantas Psicólogas? Psicologia: Ciência e Profissão, 4, 6-12

Sindicato dos Psicólogos do Estado de São Paulo, Conselho Regional de Psicologia - 6 Região (1984). $\underline{\text { O Perfil do }}$ Psicólogo no Estado de São Paulo. São Paulo: Cortez.

Recebido em 06/07/2001

Revisado em 24/10/2001

Aceito em 30/10/2001 